\title{
Uso de bioativador associado à dosagens de fertilizante fosfatado na cultura do milho
}

\author{
César Ferreira SANTOS ${ }^{1 *}$, Renato Soares OLIVEIRA ${ }^{1}$, Sheila Isabel do Carmo PINTO ${ }^{1}$ \\ ${ }^{1}$ Instituto Federal de Educação, Ciência e Tecnologia de Minas Gerais, Bambuí, MG, Brasil. \\ *E-mail: agronomocesar.santos@gmail.com
}

(ORCID: 0000-0001-6745-518; 0000-0001-8879-7269; 0000-0003-2664-9302)

\begin{abstract}
Recebido em 20/06/2020; Aceito em 05/01/2021; Publicado em 10/02/2021.
RESUMO: Os gastos com fertilizantes representam a maior parte dos custos de produção de grãos no Brasil. Cerca de $70 \%$ dos fertilizantes fosfatados adicionados aos solos são indisponibilizados pela fixação de $\mathrm{P}$ em constituintes mineralógicos dos solos tropicais. Novas tecnologias têm sido desenvolvidas visando reduzir esta fixação por meio da utilização de bioativadores de solo e planta. O presente trabalho teve por objetivo avaliar o efeito do bioativador e doses de fertilizante fosfatado sobre a produção do milho. O experimento foi conduzido no município de Bambuí em delineamento de blocos casualizados, com oito tratamentos e cinco repetições, totalizando quarenta unidades experimentais. Cada unidade experimental foi composta por quatro linhas de plantio com sete metros de comprimento, com espaçamento entre linhas de cinquenta centímetros. As variáveis avaliadas foram: altura das plantas, altura de inserção das espigas, diâmetro do colmo, comprimento da espiga, diâmetro da espiga, número de fileiras por espiga, número de grãos por fileira, massa de mil grãos, produtividade e os teores de $\mathrm{P}$ e $\mathrm{K}$ no solo. Nas condições em que o trabalho foi desenvolvido, observou-se que a adubação completa sem adição de bioativador proporcionou maior desenvolvimento vegetativo das plantas de milho, no entanto, sem conversão em aumento de produtividade.
\end{abstract}

Palavras-chave: fósforo; bioestimulante; produtividade.

\section{Use of bioactivator associated to phosphate fertilizer doses in corn culture}

\begin{abstract}
Fertilizer expenditures represent the bulk of grain production costs in Brazil. About $80 \%$ of the phosphate fertilizers added to the soils are consumed by fixing $\mathrm{P}$ to mineralogical constituents of the tropical soils. New technologies have been developed to reduce this fixation through the use of soil and plant bioactivators. The objective of this work was to evaluate the effect of the bioactivator and doses of phosphate fertilizer on maize production. The experiment was conducted in a randomized complete block design with eight treatments and five replicates, totaling forty experimental units. Each experimental unit was composed of four planting lines with seven meters in length, spaced between lines of fifty centimeters. The variables evaluated were: plant height, ear insertion height, stem diameter, ear length, ear diameter, number of rows per ear, number of grains per row, mass of one thousand grains, productivity and $\mathrm{P}$ and $\mathrm{K}$ in soil. Under the conditions in which the work was developed, it was observed that the complete fertilization without addition of bioactivator provided greater vegetative development of the corn plants, however, without conversion in increase of productivity.
\end{abstract}

Key words: phosphorus; biostimulant; productivity.

\section{INTRODUÇÃO}

O milho é um dos cereais mais cultivados em todo o mundo, fornecendo diversos produtos, usados para a alimentação humana e animal. É fonte de matéria prima para a indústria e apresenta enorme importância econômica no cenário agropecuário brasileiro (FRAZÃO et al., 2014).

Para a safra 2019/2020, em termos de área plantada, o milho poderá ocupar 17.538 mil hectares, com uma produção de 98,38 milhões de toneladas e com uma média nacional de $5,28 \mathrm{t} \mathrm{ha}^{-1}$ (CONAB, 2019). Segundo a Conab, a produtividade média para o estado de Minas Gerais, nessa mesma safra, poderá atingir $6,31 \mathrm{t} \mathrm{ha}^{-1}$, com uma área de 2,34 milhões de hectares e produção de 14,78 milhões de toneladas de milho, somando-se a safra e a safrinha.

A produtividade desta cultura vem aumentando ano após ano, e os grandes países produtores, como Estados Unidos e Brasil, atingiram esses ganhos graças ao aumento do uso de fertilizantes minerais e à eficiência na utilização de novas tecnologias. De acordo com a Associação Nacional para Difusão de Adubos (ANDA), o consumo de fertilizantes "NPK" no Brasil aumentou na ordem de $150 \%$ no período de 2000 a 2010. Nesse mesmo período, a produção de grãos aumentou 160\% (MACHADO et al., 2013).

Com o aumento no consumo de fertilizantes e corretivos, práticas e recomendações que promovam a otimização e o uso mais eficiente dos fertilizantes para garantir a competitividade do agricultor, vem sendo estudadas.

Os solos de "cerrado" no Brasil, de acordo com Lopes et al. (2004) e Broggi et al. (2011), constituem-se, em sua maioria, de Latossolos altamente intemperizados e Argissolos, com sérias limitações à produção de alimentos, no que diz respeito à baixa fertilidade natural do solo. Freitas et al. (2004) relatam que os solos dos Cerrados são ácidos, com baixa capacidade de troca de cátions e retenção de 
umidade, apresentando deficiência generalizada de nutrientes, sobretudo de fósforo $(\mathrm{P})$.

Os valores muito baixos de $\mathrm{P}$ disponível são, provavelmente, a limitação mais crítica para o crescimento das plantas nestas regiões. Devido ao extremo processo de intemperização, os minerais desses solos constituem um forte dreno de fosfato, que com o passar do tempo se torna o chamado P envelhecido ou fixado (HERNÁNDEZ; MEURER, 1998; PINTO et al., 2013).

Segundo Gatiboni et al. (2005), cerca de 80\% dos fertilizantes fosfatados adicionados aos solos são consumidos pela fixação de P em constituintes mineralógicos, sobretudo, óxidos de ferro e de alumínio dos solos ácidos intemperizados das regiões tropicais. Atualmente a alternativa comumente adotada por técnicos e pesquisadores é a aplicação de doses elevadas de P ao solo, visando ocupar os sítios de adsorção de fosfato e assim o excedente será disponibilizado para as culturas (VILAR et al., 2010). O fato é que, gastos com a adubação fosfatada passam a representar parte considerável do custo das lavouras na região do Cerrado, e variam dependendo da fonte de P utilizada e do prazo considerado para o retorno do investimento (SOUSA et al., 2002). Outro agravante para o uso de elevadas quantidades de $\mathrm{P}$ diz respeito à limitação de reservas desse elemento e possível escassez ainda neste século (GILBERT, 2009).

Diante desta situação, torna-se importante a realização de pesquisas e o uso de novas tecnologias que possam minimizar essas perdas, contribuindo para a redução da aplicação de fertilizantes fosfatados e, consequentemente do custo de produção, além de proporcionar um menor impacto ambiental. Cabe mencionar que os bioativadores de solo e planta são produtos comercializados como capazes de promover o aumento da vitalidade e equilíbrio dos sistemas biológicos de produção, e numa definição mais científica, são substâncias orgânicas complexas, capazes de modificar o crescimento das plantas (BINSFELD et al., 2014). Especificamente no caso do fosfato, os bioativadores ocupam os sítios de adsorção deste, aumentando a sua disponibilidade para as plantas, otimizando o uso de fertilizante e aumentando a atividade microbiológica do solo (ASSIS et al., 2014).

Apesar de relatos de sucesso desta tecnologia por técnicos e representantes comerciais de empresas, ainda são escassos trabalhos científicos disponíveis na literatura que comprovem a capacidade dos bioativadores aumentarem a disponibilidade de nutrientes no solo, principalmente o P. Neste contexto, o presente trabalho teve por objetivo avaliar o efeito de um bioativador e diferentes dosagens de fertilizante fosfatado sobre a produção da cultura do milho em solo de fertilidade construída no centro oeste de Minas Gerais.

\section{MATERIAL E MÉTODOS}

O experimento foi conduzido em uma fazenda de produção comercial de grãos, no município de Bambuí, na região centro-oeste de Minas Gerais, no ano agrícola 2017/2018. O solo da área experimental é classificado como Latossolo Vermelho distroférrico cambissólico, de textura argilosa (SANTOS et al., 2013). De acordo com a classificação de Köppen o clima da região é do tipo subtropical úmido, com temperatura média anual de $21,7^{\circ} \mathrm{C}$ e precipitação pluviométrica média anual de $1272,1 \mathrm{~mm}$
(ALVES, 2008). Na área experimental é empregado o sistema de plantio direto há quinze anos e a cultura anterior foi o trigo.

Para a caracterização da fertilidade do solo, efetuou-se a amostragem de solo na profundidade 0 a $0,20 \mathrm{~m}$ (Tabela 1 ).

Tabela 1. Análise química do solo da área experimental (camada 0$0,20 \mathrm{~m}$ )

Table 1. Soil chemical properties of the experimental area in the 0 $0.20 \mathrm{~m}$ soil depth

\begin{tabular}{|c|c|c|c|c|c|c|}
\hline \multirow{2}{*}{$\begin{array}{l}\mathrm{pH} \\
\mathrm{H}_{2} \mathrm{O}\end{array}$} & $\mathrm{P}$ & $\bar{K}$ & $\mathrm{Ca}$ & $\mathrm{Mg}$ & $\mathrm{Al}$ & $\overline{\mathrm{H}+\mathrm{Al}}$ \\
\hline & \multicolumn{6}{|c|}{$---m g d^{-3}---$} \\
\hline 6,4 & 8,7 & 190,0 & 4,58 & 1,63 & 0,0 & 2,36 \\
\hline \multirow{2}{*}{\multicolumn{2}{|c|}{$\mathrm{V}$ m }} & SB & $t$ & $\mathrm{~T}$ & M.O & C.O. \\
\hline & & \multicolumn{3}{|c|}{$-----\mathrm{cmol}_{\mathrm{C}} \mathrm{dm}^{-3}-$} & \multicolumn{2}{|c|}{--dag kg-1_- } \\
\hline 74 & 0,0 & 6,7 & 6,7 & 9,1 & 3,37 & 1,95 \\
\hline \multirow{2}{*}{$\begin{array}{l}\text { Prem } \\
\mathrm{mg} \mathrm{l}^{-1}\end{array}$} & B & $\mathrm{Cu}$ & $\mathrm{Fe}$ & $\mathrm{Mn}$ & $\mathrm{Zn}$ & $\mathrm{S}$ \\
\hline & & ------m & $\mathrm{dm}^{-3}$ & & & \\
\hline 6,7 & 0,11 & 1,9 & 23,1 & 15,6 & 3,4 & 5,96 \\
\hline
\end{tabular}

P: fósforo disponível (Extrator Mehlich), K: potássio disponível, Ca: cálcio trocável, Mg: magnésio, Al: alumínio, $\mathrm{H}+\mathrm{Al}$ : acidez potencial, SB: soma de bases, t: capacidade efetiva de troca de cátions, T: capacidade de troca de cátions a $\mathrm{pH}$ 7,0, V: saturação por bases, m: saturação por alumínio, M.O.: matéria orgânica, C.O.: carbônico orgânico, Prem: P remanescente, B: boro disponível, Cu: cobre disponível, Fe: ferro disponível, Mn: manganês disponível, Zn: zinco disponível, S: enxofre.

O experimento foi instalado em delineamento de blocos casualizados, com oito tratamentos (Tabela 2) e cinco repetições, totalizando quarenta unidades experimentais.

Tabela 2. Tratamentos utilizados, combinações entre doses de fertilizantes fosfatados e bioativador

Table 2. Utilized treatments, combinations between doses of phosphate fertilizers and bioactivator

\begin{tabular}{ccccc}
\hline Tratamento & $\begin{array}{c}\mathrm{P} \\
\left(\mathrm{kg} \mathrm{ha}^{-1}\right)\end{array}$ & $\begin{array}{c}\text { Bioativador } \\
\left(\mathrm{g} \mathrm{ha}^{-1}\right)\end{array}$ & $\begin{array}{c}* \mathrm{~N} \\
\left(\mathrm{~kg} \mathrm{ha}^{-1}\right)\end{array}$ & $\begin{array}{c}* \mathrm{~B} \\
\left(\mathrm{~kg} \mathrm{ha}^{-1}\right)\end{array}$ \\
\hline T1 & 0 & 0 & 0 & 0 \\
T2 & 0 & 357,14 & 0 & 0 \\
T3 & 132 & 357,14 & 202 & 1,35 \\
T4 & 99 & 357,14 & 202 & 1,35 \\
T5 & 66 & 357,14 & 202 & 1,35 \\
T6 & 33 & 357,14 & 202 & 1,35 \\
T7 & 0 & 357,14 & 202 & 1,35 \\
T8 & 132 & 0 & 202 & 1,35 \\
\hline
\end{tabular}

*Aplicados em cobertura; Trat.: Tratamentos; P: $\mathrm{P}_{2} \mathrm{O}_{5}$; N: nitrogênio; B: boro.

Cada unidade experimental foi composta por quatro linhas de plantio com sete metros de comprimento, com espaçamento entre linhas de cinquenta centímetros. Para as avaliações foram utilizadas as duas linhas centrais de cada unidade experimental descontando-se um metro em cada extremidade.

O híbrido semeado foi o DKB 390 com a tecnologia VT PRO MAX. As principais características agronômicas do híbrido utilizado, conforme dados da empresa a qual pertence: (Ciclo: precoce; Porte da planta: 2,2 m; Inserção da espiga: 1,25 m; Stay green: bom; Empalhamento: bom; Sistema radicular: excelente; Tipo de grão: duro; Cor: amarelo/alaranjado; apresenta alto potencial produtivo e estabilidade).

Os constituintes do produto denominado bioativador são: Silicato $\mathrm{SiO}_{2}(57,5 \%), \mathrm{Al}_{2} \mathrm{O}_{3}(18,1 \%)$, Óxido de ferro $\mathrm{Fe}_{2} \mathrm{O}_{3}$ (4,5 \%), Cálcio CaO (4,0 \%), Magnésio $\mathrm{MgO}$ (4,0\%), $\mathrm{K}_{2} \mathrm{O}(2,0 \%)$, Sódio $\mathrm{Na}_{2} \mathrm{O}(0,5 \%)$, Titânio $\mathrm{TiO}_{2}(0,3 \%)$, Ignição Loss $(9,1 \%)$.

A dessecação da área experimental foi realizada trinta dias 
antes do plantio utilizando herbicidas a base de Glyphosato $480 \mathrm{~g} \mathrm{~L}^{-1}$ e Atrazina $500 \mathrm{~g} \mathrm{~L}^{-1}$, na dosagem de 2 e $4 \mathrm{~L} \mathrm{ha}^{-1}$, respectivamente.

Vinte dias antes do plantio foi realizada a aplicação do bioativador de solo utilizando-se um pulverizador costal com um volume de calda de $2 \mathrm{~L}$ para cada unidade experimental com área de $14 \mathrm{~m}^{2}$. Foi pesado 0,5 $\mathrm{g}$ do bioativador em balança de precisão, diluído em 2 L de água destilada, sendo esta a dosagem utilizada em cada unidade experimental $\left(357,14 \mathrm{~g} \mathrm{ha}^{-1}\right)$.

A adubação recomendada foi baseada na adotada pela fazenda. No plantio aplicou-se $132 \mathrm{~kg}$ de $\mathrm{P}_{2} \mathrm{O}_{5}$ e $36 \mathrm{~kg}$ de nitrogênio por hectare, sendo utilizados como fonte o superfosfato simples e sulfato de amônio, respectivamente. O tratamento das sementes foi feito com o uso de produto a base de Tiametoxam $350 \mathrm{~g} \mathrm{~L}^{-1}$ na dose de $12 \mathrm{~mL}$ para 60000 sementes. Para a semeadura foram abertos sulcos de forma manual, com cerca de $7 \mathrm{~cm}$ de profundidade, dentro de cada sulco foram distribuídos os fertilizantes de acordo com cada tratamento, cobriu-se com uma camada de 3 centímetros de solo e foram semeadas manualmente sementes de milho espaçadas no sulco de 28 em 28 centímetros, totalizando uma população de 70000 sementes ha-1.

Aos 20 dias após a semeadura foi realizado o desbaste das plantas, deixando a população recomendada para o híbrido (60000 sementes ha-1). A adubação de cobertura foi realizada no estágio V3 da planta, 20 dias após a semeadura, quando foram aplicados 202,5 kg de nitrogênio por ha-1 (fonte usada: sulfato de amônio $(20 \% \mathrm{~N})$ ), sendo distribuído manualmente na linha de plantio, com exceção do T1 e T2, onde não foi realizada adubação em cobertura. Para o controle das plantas daninhas utilizou-se os herbicidas Glyphosato $480 \mathrm{~g} \mathrm{~L}^{-1}$ e Atrazina $500 \mathrm{~g} \mathrm{~L}^{-1}$, na dosagem de 2,0 e 4,0 L ha ${ }^{-1}$ respectivamente, sendo aplicados com pulverizador manual costal.

Novamente aos 35 dias após a semeadura, foi aplicado o bioativador de planta, na dose de 0,5 grama do produto por unidade experimental $\left(357,14 \mathrm{~g} \mathrm{ha}^{-1}\right)$ com volume de calda de 2 litros para cada unidade experimental, aplicada utilizandose um pulverizador manual costal.

Aos 63 dias após a semeadura, realizou-se uma aplicação de fertilizante foliar com as seguintes garantias: $10 \% \mathrm{~N}$; $3,72 \%$ S; $0,5 \%$ B; 3,0\% Mn e 4\% Zn, na dose de $2 \mathrm{~L} \mathrm{ha}^{-1}$, como fonte de micronutrientes. Foi feita a aplicação de fungicida a base de Azoxistrobina $200 \mathrm{~g} \mathrm{~L}^{-1}+$ Ciproconazol $80 \mathrm{~g} \mathrm{~L}^{-1} \mathrm{e}$ adjuvante (Óleo mineral $756 \mathrm{~g} \mathrm{~L}^{-1}$ ) na dosagem de $0,3 \mathrm{~L} \mathrm{ha}^{-1}$ e $2,0 \mathrm{~L} \mathrm{ha}^{-1}$, respectivamente.

A colheita do milho foi realizada 160 dias após a semeadura, quando os grãos apresentavam teor de umidade em torno de $18 \%$.

\subsection{Variáveis avaliadas \\ 2.1.1. Altura da planta, de inserção de espiga e diâmetro do caule}

Foram avaliadas dez plantas por parcela, quanto à altura (determinada com o auxílio de uma trena graduada em centímetros, medindo-se do nível do solo à inserção da última folha); a altura de inserção da espiga (considerada como a distância do nível do solo ao ponto de inserção da primeira espiga) e o diâmetro do caule (medido com paquímetro digital, medindo-se no primeiro internódio da base e ápice, sendo considerada a média entre os dois extremos).

\subsubsection{Características do solo após aplicação dos tratamentos}

Para o conhecimento das características químicas do solo após ser submetido à aplicação do bioativador de solo e planta, e diferentes dosagens de $\mathrm{P}$, foram retiradas 4 amostras simples a fim de se obter uma amostra composta, na área útil de cada unidade experimental. As análises foram realizadas no Laboratório de Solos do Instituto Federal de Minas Gerais, em Bambuí.

\subsubsection{Diâmetro das espigas, comprimento, número de fileiras, número de grãos por fileira e massa de mil grãos}

Foram avaliadas em 10 espigas da área útil de cada unidade experimental, o diâmetro das espigas (determinado utilizando-se um paquímetro digital, e considerando-se a média de 3 medições) e o comprimento das espigas (determinado com o auxílio de uma trena, medindo-se as espigas longitudinalmente). Também foram avaliados $\mathrm{O}$ número de fileiras de grãos nas espigas, o número de grãos por fileira e a massa de 1000 grãos.

Para o cálculo da massa de 1000 grãos foram utilizadas para cada unidade experimental oito repetições de 100 grãos provenientes de uma porção de grãos puros. Em seguida calculou-se a variância, o desvio padrão e o coeficiente de variação dos valores obtidos nas pesagens. O resultado da determinação é calculado multiplicando-se por 10 a massa média obtida das repetições de 100 sementes (MAPA, 2009).

Em seguida foi determinada a umidade dos grãos utilizando um medidor de umidade portátil, modelo Agrologic ${ }^{\circledR}$ AL-102 ECO. As massas foram ajustadas para $13 \%$ de umidade e a produtividade por hectare estimada com base na massa dos grãos de 10 espigas e o número de plantas por hectare, e expressa em quilograma por hectare.

\subsection{Análise estatística}

Os dados foram submetidos à análise de variância e as médias agrupadas utilizando o teste de Scott-Knott a 5\% de probabilidade. As análises foram realizadas pelo programa computacional "Sistema para Análise de Variância" SISVAR (FERREIRA, 2011).

\section{RESULTADOS}

$\mathrm{Na}$ Tabela 3 são apresentados os resultados da análise de variância para as características, altura das plantas (AP), altura de inserção da espiga (AIE), diâmetro do colmo (DC), comprimento de espiga (CE), diâmetro das espigas (DE), número de fileiras por espiga (NF) e número de grãos por fileira das espigas das plantas de milho (NGF) submetidas aos diferentes tratamentos. Para todas as variáveis verificou-se efeito dos tratamentos $(\mathrm{P}<0,05)$.

Em relação à AP e à AIE o tratamento T8 (adubação recomendada sem bioativador) se destacou entre os demais proporcionando maior desenvolvimento (Figura 1). Para as características AP e AIE o tratamento que recebeu a dose completa de adubação fosfatada associada com o bioativador (T3) obteve menores valores se comparado ao tratamento com dose completa de adubação fosfatada sem adição do bioativador (T8). Os tratamentos T1 (testemunha) e T2 (somente aplicação do bioativador) apresentaram menor AIE e AP.

Os tratamentos T1 e T2 apresentaram menor desenvolvimento das espigas como pode ser observado pelo CE (Figura 2) e NGF (Figura 3). 
Tabela 3. Resumo da análise de variância para as características altura da planta (AP), altura de inserção das espigas (AIE), diâmetro do colmo (DC), comprimento de espiga (CE), diâmetro das espigas (DE), número de fileiras $(\mathrm{NF})$ e número de grãos por fileira (NGF) em função da aplicação do bioativador e doses de fertilizante fosfatado

Table 3. Analysis of variance summary of the characteristics plant height (AP), height of insertion of the corn cobs (AIE), culm diameter (DC), cob length (CE), cob diameter (DE), number of rows per cob $(\mathrm{NF})$ and number of corn grains per row (NGF) as a function of the application of bioactivator and doses of phosphate fertilizers

\begin{tabular}{|c|c|c|c|c|}
\hline FV & $\mathrm{AP}(\mathrm{m})$ & AIE (m) & \multicolumn{2}{|c|}{$\mathrm{DC}(\mathrm{mm})$} \\
\hline Trat & $0,000^{*}$ & $0,000^{*}$ & \multicolumn{2}{|c|}{$0,000^{*}$} \\
\hline Bloco & $0,000^{*}$ & $0,000^{*}$ & \multicolumn{2}{|c|}{$0,790^{\text {ns }}$} \\
\hline Média & 2,473 & 1,542 & \multicolumn{2}{|c|}{28,353} \\
\hline $\mathrm{CV}_{0} \%$ & 2,56 & 4,61 & \multicolumn{2}{|c|}{25,65} \\
\hline $\mathrm{FV}$ & $\mathrm{CE}(\mathrm{cm})$ & $\mathrm{DE}(\mathrm{mm})$ & $\mathrm{NF}$ & NGF \\
\hline Trat & $0,000^{*}$ & $0,004^{*}$ & $0,003^{*}$ & $0,000^{*}$ \\
\hline Bloco & $0,008^{\text {ns }}$ & $0,686^{\text {ns }}$ & $0,114^{\mathrm{ns}}$ & $0,002^{*}$ \\
\hline Média & 16,808 & 54,964 & 18,345 & 35,262 \\
\hline CV\% & 8,83 & 3,88 & 9,20 & 9,62 \\
\hline
\end{tabular}

* significativo a $5 \%$ de probabilidade pelo teste $\mathrm{F}$. ${ }^{\text {ns }}$ não significativo a $5 \%$ de probabilidade pelo teste F. CV (coeficiente de variação), FV: fonte de variação, Trat.: tratamentos.

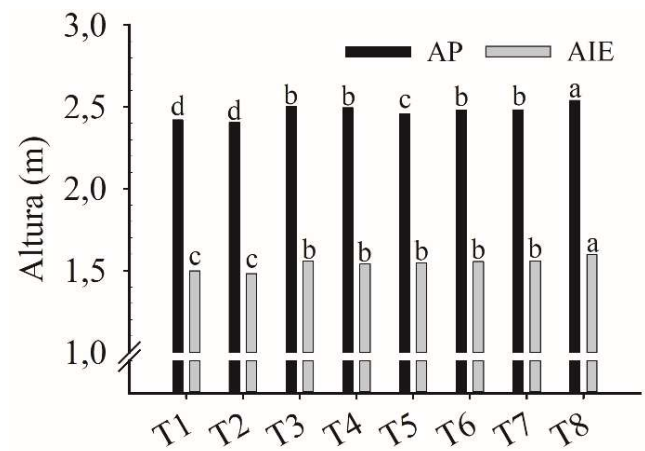

Figura 1. Valores médios AP, e AIE em função da aplicação do bioativador e dose de fertilizante fosfatado. Médias seguidas pela mesma letra não diferem entre si, para cada variável, pelo teste Scott-Knott a 5\% de probabilidade.

Figure 1. Mean values of AP and AIE as a function of the application of bioactivator and doses of phosphate fertilizers. Means followed by the same letter do not differ within each variable at $5 \%$ of probability by the Scott-Knott test.

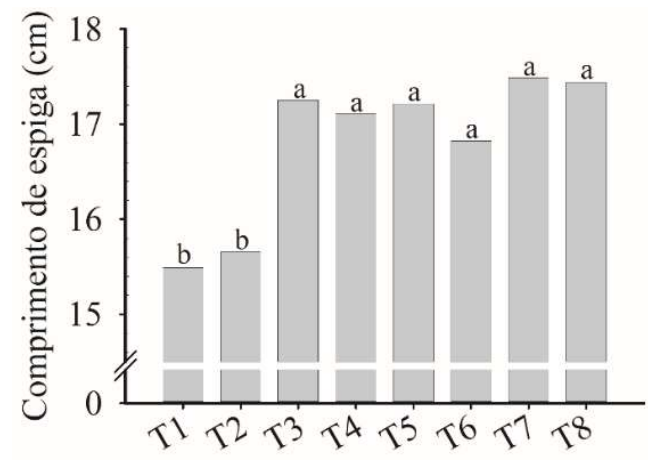

Figura 2. Valores médios de $\mathrm{CE}$ em função da aplicação do bioativador e dose de fertilizante fosfatado.

Médias seguidas pela mesma letra não diferem entre si pelo teste Scott-Knott a $5 \%$ de probabilidade.

Figure 2. Mean values of $\mathrm{CE}$ as a function of the application of bioactivator and doses of phosphate fertilizers. Means followed by the same letter do not differ at $5 \%$ of probability by the Scott-Knott test.

Quanto ao NF, os tratamentos T1, T2 e T6 se destacaram apresentando as menores médias para estes parâmetros
(Figura 3).

Os tratamentos T1 (testemunha) e T2 (somente aplicação do bioativador) apresentaram menor DC, enquanto que para a varável $\mathrm{DE}$, os tratamentos T1, T2 e T6 se destacaram apresentando as menores médias (Figura 4).

Embora tenha sido constatado efeito dos tratamentos sobre as características de crescimento das plantas e das espigas, estes não foram suficientes para alterar a produtividade da cultura $(\mathrm{P}>0,05)$ (Tabela 4).

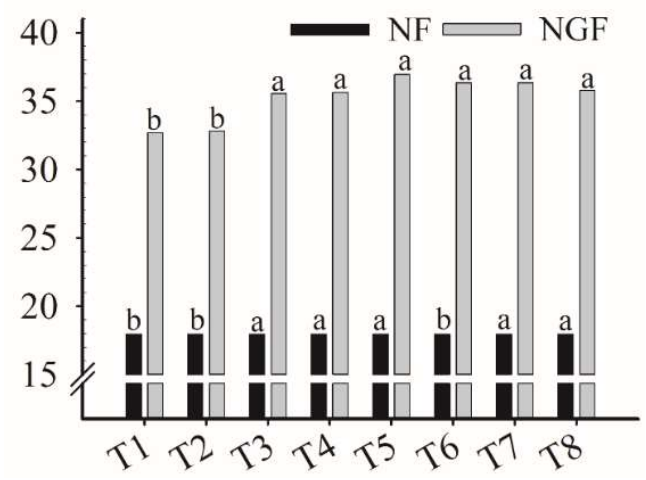

Figura 3. Valores médios de NF e NGF em função da aplicação do bioativador e dose de fertilizante fosfatado. Médias seguidas pela mesma letra não diferem entre si, para cada variável, pelo teste Scott-Knott a 5\% de probabilidade.

Figure 3. Mean values of NF and NGF as a function of the application of bioactivator and doses of phosphate fertilizers. Means followed by the same letter do not differ within each variable at $5 \%$ of probability by the Scott-Knott test.

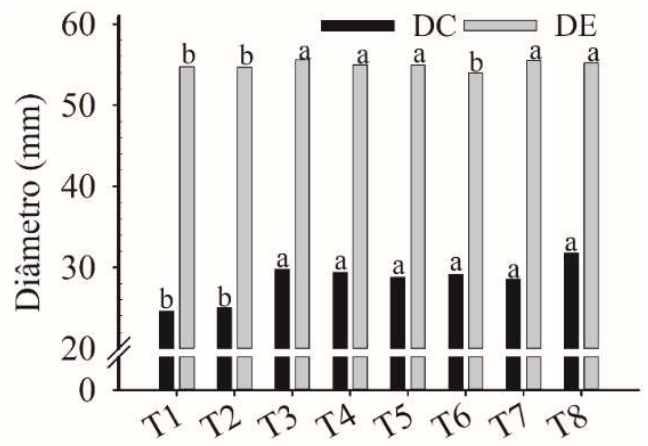

Figura 4. Valores médios de DC e DE em função da aplicação do bioativador e dose de fertilizante fosfatado. Médias seguidas pela mesma letra não diferem entre si, para cada variável, pelo teste Scott-Knott a 5\% de probabilidade.

Figure 4. Mean values of DC and DE as a function of the application of bioactivator and doses of phosphate fertilizers. Means followed by the same letter do not differ within each variable at $5 \%$ of probability by the Scott-Knott test.

Tabela 4. Resumo da análise de variância para as características massa (MMG) e produtividade em função da aplicação do bioativador e doses de fertilizante fosfatado.

Table 4. Analysis of variance summary of the characteristics weight (MMG) and productivity as a function of the application of bioactivator and doses of phosphate fertilizers.

\begin{tabular}{ccc}
\hline Fonte de variação & MMG $(\mathrm{g})$ & Produtividade $\left(\mathrm{kg} \mathrm{ha}^{-1}\right)$ \\
\hline Tratamento & $0,6758^{\mathrm{NS}}$ & $0,0815^{\mathrm{NS}}$ \\
Bloco & $0,5782^{\mathrm{NS}}$ & $0,3508^{\mathrm{NS}}$ \\
\hline Média Geral & 321,0135 & 13237,586 \\
$\mathrm{CV}(\%)$ & 6,08 & 10,03 \\
\hline Ns não significativo a $5 \%$ de probabilidade pelo teste F. CV (coeficiente de
\end{tabular}
variação). 
Na Tabela 5 é apresentado o resumo da análise de variância para os teores de $\mathrm{P}$ e $\mathrm{K}$ no solo após a realização do experimento. Somente verificou-se efeito dos tratamentos para os teores de $\mathrm{K}$ no solo $(\mathrm{P}<0,05)$.

Tabela 5. Resumo da análise de variância para as características químicas do solo após a realização do experimento.

Table 5. Analysis of variance summary of the soil chemical characteristics after the experiment.

\begin{tabular}{lll}
\hline Fontes variação & $\mathrm{P}\left(\mathrm{mg} \mathrm{dm}^{-3}\right)$ & $\mathrm{K}\left(\mathrm{mg} \mathrm{dm}^{-3}\right)$ \\
\hline Tratamento & $0,8295^{\mathrm{NS}}$ & $0,0001^{*}$ \\
Bloco & $0,6324^{\mathrm{NS}}$ & $0,5644^{\mathrm{NS}}$ \\
\hline Média Geral & 9,891 & 92,83 \\
$\mathrm{CV}(\%)$ & 58,21 & 12,62 \\
\hline
\end{tabular}

*significativo a $5 \%$ de probabilidade pelo teste $\mathrm{F}$. Ns não significativo a $5 \%$ de probabilidade pelo teste $\mathrm{F}$. $\mathrm{CV}=$ coeficiente de variação. $\mathrm{P}=\mathrm{P}$ (Extrator Mehlich), $\mathrm{K}=$ potássio.

Considerando a análise química do solo, a qual foi realizada antes da instalação do experimento, o teor de $\mathrm{P}(8,7$

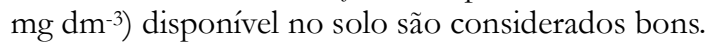

O solo das parcelas experimentais testemunhas, sem nenhuma adubação (T1) e que somente recebeu a aplicação do bioativador (T2), apresentou maior disponibilidade de K em relação ao solo das demais parcelas (Figura 5).

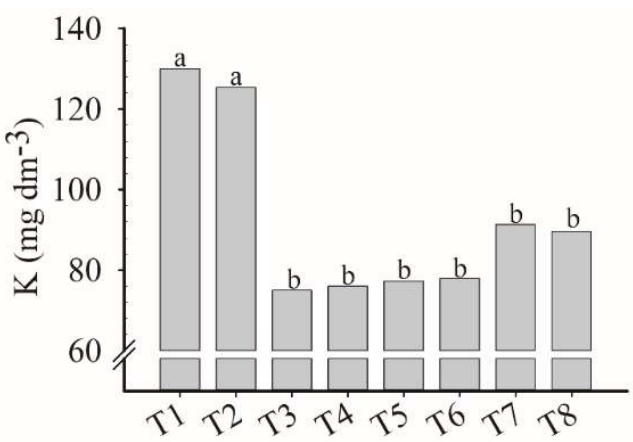

Figura 5. Valores médios para o teor de potássio do solo após a realização do experimento. Médias seguidas pela mesma letra, não diferem entre sipelo teste Scott-Knott a 5\% de probabilidade.

Figure 5. Mean values of potassium concentration in the soil after the experiment. Means followed by the same letter do not differ at $5 \%$ of probability by the Scott-Knott test.

\section{DISCUSSÃO}

Com relação à AP e à AIE apresentadas na Figura 1, o tratamento T8, somente com a adubação para a cultura se destacou, evidenciando, portanto, que, a aplicação do bioativador influenciou negativamente a AP e a AIE como pode ser verificado comparando-as às obtidas no tratamento (T3) em que além da adubação foi aplicado o bioativador.

Em trabalho realizado por Coelho et al. (2012), onde analisaram a resposta do milho à adubação fosfatada, os autores verificaram maior altura das plantas para a dose de $135 \mathrm{~kg} \mathrm{ha}^{-1} \mathrm{de}_{2} \mathrm{O}_{5}$, dose semelhante à aplicada via adubação no tratamento T8 (132 kg ha-1 de $\left.\mathrm{P}_{2} \mathrm{O}_{5}\right)$. Gomide et al. (2014) encontraram valores médios para altura de planta e altura de inserção de espiga em experimento realizado com o híbrido $\mathrm{DKB} 390$, entre 2,64 m e 1,63 m, respectivamente, estes valores foram superiores aos encontrados no presente trabalho. Já Zucareli et al. (2011) encontraram alturas de plantas de 2,25 $\mathrm{m}$ e altura de inserção de espiga de $1,25 \mathrm{~m}$, sendo estes, valores inferiores às médias obtidas neste estudo.

Respostas nas variáveis AP e AIE à aplicação de fertilizantes são muito variáveis entre os trabalhos, seja pelo nível de fertilidade do solo usado, sobretudo em relação ao teor de matéria orgânica, e ainda características intrínsecas ao genótipo de milho utilizado na pesquisa.

Os tratamentos onde foram aplicados somente $\mathrm{O}$ bioativador (T2) ou nenhum insumo (T1), obtiveram AP, AIE, DC, CE, DE, NF e NGF inferior aos demais. Portanto cabe ressaltar a importância da adubação, principalmente nitrogenada, no desenvolvimento vegetativo do milho. Plantas adequadamente nutridas em $\mathrm{N}$ têm maior desenvolvimento vegetativo, uma vez que o nutriente influencia diretamente a divisão e expansão celular e o processo fotossintético (BÜLL, 1993). No caso específico do DC, Magalhães; Jones (1990) ressaltam que o colmo funciona como estrutura de reserva, ocorrendo translocação de fotoassimilados do colmo para os grãos, sendo uma variável muito relacionada à produtividade da cultura. No entanto, embora os tratamentos (T1) e (T2) tenham apresentado menor desenvolvimento vegetativo em relação a todas as variáveis supracitadas, este não comprometeu a produtividade da cultura.

O comportamento observado no tratamento associando a dose padrão de $\mathrm{P}\left(132 \mathrm{~kg} \mathrm{ha}^{-1} \mathrm{de} \mathrm{P}_{2} \mathrm{O}_{5}\right)$ e bioativador (T3) com menor AP e AIE, em relação ao tratamento com a dose padrão (132 kg ha-1 de $\mathrm{P}_{2} \mathrm{O}_{5}$ ) sem bioativador (T8), evidencia que a aplicação do bioativador juntamente com a adubação recomendada reduziu os efeitos do fertilizante, característica esta indesejável quando se aplica $\mathrm{P}$ ao solo, sobretudo do ponto de vista econômico. Este comportamento foi o oposto ao observado por Steffen (2014), que testou o efeito de um bioativador de solo e planta no desenvolvimento inicial de plantas de trigo e obteve um aumento significativo nos parâmetros de desenvolvimento da cultura, obtendo plantas com maior altura, massa da parte aérea e raízes, além de maior desenvolvimento das espiguetas.

A MMG e a produtividade obtidos nos tratamentos não apresentaram efeito dos tratamentos, provavelmente devido ao sistema de plantio direto consolidado, com bom padrão de fertilidade do solo, que foi capaz de manter as necessidades nutricionais da cultura, durante todo o ciclo.

Alovisi et al. (2014) também obtiveram resultados semelhantes em trabalho com diferentes doses de pó basalto, com ou sem adição de bioativador, em que os tratamentos não influenciaram na produtividade da cultura do milho. Já Nascente; Cobucci (2014) em trabalho com aplicação de bioativador de solo e planta sob diferentes dosagens de adubação fosfatada na cultura do feijão, concluíram que o bioativador independentemente da combinação com as doses de $\mathrm{P}$ proporcionou maiores valores de rendimento de grãos do feijão em relação aos tratamentos sem adição do produto. A aplicação do bioativador permitiu maior rendimento de grãos até mesmo com a menor dose de $\mathrm{P}$ aplicada.

Os teores de $\mathrm{P}$ disponível após a aplicação dos tratamentos são considerados adequados de acordo com Ribeiro et al. (1999). Assim, como não foram observados sintomas que caracterizam a deficiência de $\mathrm{P}$ na fase reprodutiva do milho, pode-se afirmar que este teor proporcionou suporte de $\mathrm{P}$ necessário para que as plantas de milho crescessem e se desenvolvessem até o florescimento, não apresentando diferenças para as variáveis MMG e produtividade.

A adição do bioativador, portanto, não foi capaz de aumentar os teores de P disponível no solo. Assim, embora alguns trabalhos mencionem que os bioativadores ocupam os sítios de adsorção de $\mathrm{P}$, aumentando a sua disponibilidade $(\mathrm{P})$ 
para as plantas, otimizando o uso de fertilizante (ASSIS et al., 2014), este papel não foi verificado no presente trabalho.

Os tratamentos testemunhas T1 e T2 apresentaram maiores teores de potássio disponíveis, muito provavelmente devido à menor extração do nutriente pela cultura uma vez que embora a produtividade tenha sido semelhante à dos demais tratamentos, as plantas dos tratamentos testemunhas se desenvolveram menos e, portanto, exportaram menor quantidade do nutriente do solo.

De acordo com Coelho e França (1995) a extração de potássio do solo pelo milho aumenta linearmente com o aumento do desenvolvimento da planta, isto explica o motivo da maior disponibilidade de potássio nos tratamentos em que obtiveram menores médias para as variáveis, como: AP, AIE, DC, CE, DE, NGF e NF.

\section{CONCLUSÕES}

A adubação completa sem adição de bioativador proporciona maior desenvolvimento vegetativo das plantas de milho, no entanto, sem conversão em aumento de produtividade.

A adição de bioativador associado a dosagens diferenciadas de $\mathrm{P}$ ou até mesmo sem $\mathrm{P}$, mas com aplicação da adubação nitrogenada, proporciona desenvolvimento análogo das espigas de milho.

A adição de bioativador reduz os efeitos da adubação completa, proporcionando menor crescimento das plantas e espigas de milho.

A adição do bioativador não é capaz de aumentar os teores de $\mathrm{P}$ e potássio disponíveis no solo.

Embora os resultados obtidos não sejam motivadores, pesquisas com o mesmo intuito deverão ser realizadas, sobretudo em solos de mineralogia contrastante com diferentes níveis de fertilidade e sistemas de plantio.

\section{REFERÊNCIAS}

ALOVISI, A. M. T.; ARAÚJO, L. R. C.; TAQUES, M. M.; TERUEL, H. H. Produtividade do milho em resposta à utilização de pós de rochas. In: ENEPE UFGD, 8, 2014. Dourados. Disponível em: $<$ http://www.enepex.com.br/apresentacao $>$ Acessado em: junho, 2019.

ALVES, K. A.; ROSA, R. Espacialização de dados climáticos do cerrado mineiro. Horizonte Científico, Uberlândia, v.8, n. 1, p.1-28, 2008.

ASSIS, R. T.; OLIVEIRA, I. J. V.; MORAIS, A. M.; MORAIS NETO, A. A.; DIAS, S. H. Novas tecnologias para a agricultura brasileira. Araxá: Instituto de ciências da saúde, agrárias e humanas (ISAH). Araxá, 2014. 7p. (Circular Técnica, 2). Disponível em: http://site.uniaraxa.edu.br/wp-

content/uploads/2014/09/novas-tecnologias-para-aagricultura-brasileira.pdf

BINSFELD, J. A.; BARBIERI, A. P. P.; HUTH, C.; CABRERA, I. C.; HENNING, L. M. M. Use of bioactivator, biostimulant and complex of nutrients in soybean seeds. Pesquisa Agropecuária Tropical, Goiânia, v. 44, n. 1, 2014. DOI: https://doi.org/10.1590/S1983-40632014000100010.

BROGGI, F.; OLIVEIRA, A. C.; FREIRE, F. J.; FREIRE, M. B. G. S.; NASCIMENTO, C. W. A. Fator capacidade de fósforo em solos de Pernambuco mineralogicamente diferentes e influência do $\mathrm{pH}$ na capacidade máxima de adsorção. Ciência e Agrotecnologia, Lavras, v. 35, n. 1, p. 77-83, 2011. DOI: http://dx.doi.org/10. 1590/S141370542011000100009.

BÜLL, L. T. Nutrição mineral do milho. In: BÜLL, L. T.; CANTARELLA, H. (Ed.). Cultura do milho: fatores que afetam a produtividade. Piracicaba: POTAFOS, 1993. p. 63-145.

COELHO, A. M.; FRANÇA, G. E. Seja o doutor do seu milho: nutrição e adubação. 2 ed. Piracicaba: Potafos, 1995. 9p.

COELHO, C. C. R.; COUTINHO, P. W. R.; CONCEIÇÃO, A. G. C.; BEZERRA, M. G. A.; LIMA, S. V.; PINHEIRO, G. F. C.; LIMA, J. V.; SALDANHA, E. C. M. Resposta do milho à adubação fosfatada no Nordeste do Pará. In: Congresso nacional de milho e sorgo, 29, 2012, Águas de Lindóia. Disponível em: <http://www.abms.org.br/29cn_milho/06289.pdf> Acessado em: junho, 2019.

CONAB_Companhia Nacional de Abastecimento. Acompanhamento da safra brasileira de grãos: safra 2019/2020. Disponível em: <http://www.conab.gov.br. Acesso em: novembro de 2019.

FERREIRA, D. F. Sisvar: a computer statistical analysis system. Ciência e Agrotecnologia, Lavras, v. 35, n. 6, p. 1039-1042, $2011 . \quad$ DOI: http://dx.doi.org/10.1590/S1413-70542011000600001.

FRAZÃO, J. J.; SILVA, A. R.; SILVA, V. L.; OLIVEIRA, V. A.; CORRÊAS, R. S. Fertilizantes nitrogenados de eficiência aumentada e ureia na cultura do milho. Revista Brasileira de Engenharia Agrícola e Ambiental, Campina Grande, v. 18, n. 12, p. 1262-1267, 2014. DOI: http://dx.doi.org/10.1590/1807-

1929/agriambi.v18n12p1262-1267

FREITAS, P. L.; BERNARDI, A. C. C.; MANZATTO, C. V.; RAMOS, D. P.; DOWICH, I.; LANDRES, J. N. Comportamento físico-químico dos solos de textura arenosa e média do oeste baiano. Rio de Janeiro: Embrapa Solos, 2004. 7p. (Comunicado Técnico, 27).

GATIBONI, L. C.; KAMINSKI, J.; SANTOS, D. R. Alterations in soil phosphorus forms after successive extractions with Mehlich-1, mehlich-3 and anion exchange resin methods. Revista Brasileira de Ciência do Solo, Viçosa, v. 29, n. 3, p. 363-371, 2005. DOI: http://dx.doi.org/10.1590/S0100-06832005000300006.

GILBERT, N. The disappearing nutrient. Nature, v. 461, n. 8, p. 716-718, 2009.

GOMIDE, R. L.; ALBUQUERQUE, P. E. P.; MAGALHÃES, P. C.; RIBEIRO, D. P.; DOMINGOS, G. F.; PORTUGAL, A. F.; BASTOS, E. A. Controle e medição do estresse por restrição hídrica em genótipos de milho para a avaliação fenotípica de tolerância à seca em condições climáticas do Norte de Minas Gerais. In: Congresso nacional de milho e sorgo, 30, 2014. Salvador (BA). Anais... Disponível em: <http:// http://www.abms.org.br/eventos_anteriores/cnms2014 _trabalhos/trabalhos.html > Acessado em: 09 fev. 2021.

HERNÁNDEZ, J.; MEURER, E. J. Adsorção de fósforo e sua relação com formas de ferro em dez solos do Uruguai. Revista Brasileira de Ciência do Solo, Campinas, v. 22, p. 223-230, $1998 . \quad$ DOI: http://dx.doi.org/10.1590/S0100-06831998000200007.

LOPES, A. S.; WIETHOLTER, S.; GUILHERME, L. R. G.; SILVA, C. A. Sistema Plantio Direto: bases para o manejo da fertilidade do solo. São Paulo: ANDA, 
2004. 110p.

MACHADO, V. J.; SOUZA, C. H. E.; LANA, R. M. Q.; SILVA, A. A.; RIBEIRO, V. J. Produtividade da cultura do milho em função de adubação nitrogenada em cobertura. Revista Verde, Mossoró, v. 8, n. 5, p. 93-104, 2013. ISSN 1981-8203.

MAGALHÃES, P. C.; JONES, R. Aumento de fotoassimilados na taxa de crescimento e peso final dos grãos de milho. Pesquisa Agropecuária Brasileira, Brasília, v. 25, n. 12, p. 1747-1754, 1990.

MINISTÉRIO DA AGRICULTURA, PECUÁRIA E ABASTECIMENTO. Regras para análise de sementes. 1ed. Brasília: MAPA, 2009. 398p.

NASCENTE, S.; COBUCCI, T. Phosphate fertilization in the soil and $P$ energetic application in the grain yield of common bean. In: World Congress of Soil Science, 20. 2014.

PINTO, F. A.; SOUZA, E. D.; PAULINO, H. B.; CURI, N.; CARNEIRO, M. A. C. P-sorption and desorption in savanna Brazilian soils as a support for phosphorus fertilizer management. Ciência e Agrotecnologia, Lavras, v. 37, n. 1, p. 521-530, jan./fev. 2013. http:/ /dx.doi.org/10.1590/S1413-70542013000600005.

RIBEIRO, A. C.; GUIMARÃES, P. T. G.; ALVARES, V. H. Recomendação para o uso de corretivos e fertilizantes em Minas Gerais: 5a aproximação. Viçosa-MG: UFV, 1999. 359p.

RIBEIRO, D. P. Avaliação fenotípica de híbridos de milho cultivados sob regimes hídricos para as condições climáticas para o norte de Minas Gerais. 2011. Monografia (Bacharel em Agronomia) Universidade Estadual de Montes Claros, Janaúba, 2011.

SANTOS, H. G.; JACOMINE, P. K. T.; ANJOS, L. H. C.; OLIVEIRA, V. A.; LUMBRERAS, J. F.; COELHO, M. R.; ALMEIDA, J. A.; CUNHA, T. J. F.; OLIVEIRA, J. B. Sistema brasileiro de classificação de solos. 3 ed. Brasília: Embrapa, 2013. 353p.

SOUSA, D. M. G.; LOBATO, E.; REIN, T. A. Adubação com fósforo. In: SOUSA, D. M. G.; LOBATO, E. (Eds). Cerrado: correção do solo e adubação. Planaltina: Embrapa Cerrados, 2002. p. 147-168.

STEFFEN, R. B. Efeito do P energetic ${ }^{\circledR}$ P e $K$ no desenvolvimento inicial de plantas de trigo. In: Salão de iniciação científica e inovação tecnológica, 3. 2014, Porto Alegre. Anais... Porto Alegre: Fepagro, 2014. p. 165.

VILAR, C. C.; COSTA, A. C. S.; HOEPERS, A.; SOUZA JUNIOR, I. G. Capacidade máxima de adsorção de fósforo relacionada a formas de ferro e alumínio em solos subtropicais. Revista Brasileira de Ciência do Solo. Viçosa, v. 34, p. 1059-1068, 2010. DOI: https://doi.org/10.1590/S0100-06832010000400006

ZUCARELI, C.; CIL, I. R.; PRETE, C. E. C.; PRANDO, A. M. Eficiência agronômica da inoculação à base de Pseudomonas fluorescens na cultura do milho. Revista Agrarian, Dourados, v. 4, n. 13, p.152-157, maio 2011. ISSN 1984-2538. 